\title{
EL INFINITO EN LA OBRA DE JORGE LUIS BORGES
}

Borges $^{1}$ ha hablado del efecto sobrecogedor que produce el mapa dentro del mapa en la obra de Josiah Royce, The world and the individual, el drama dentro del drama en Hamlet, la novela dentro de la novela en el Quijote y las parejas inclusiones de Las mil y una noches y del Ramayana². Ellas sugieren a los lectores o espectadores, que se consideran seres reales, su posible condición de entes imaginarios. Diríamos que en este texto está la clave de toda su obra. Acosado por un mundo demasiado real:3 pero que al mismo tiempo carece de sentido, busca liberarse de su obsesión creando otro mundo de fantasmagorías, tan coherente y nítido que, de rechazo, nos hace dudar de la misma realidad en que nos apoyábamos.

Para socavar nuestra creencia en un existir concreto, Borges ataca los conceptos fundamentales en que se basa la seguridad del propio vivir: el universo, la personalidad y el tiempo. Además, nos hace sentir constantemente la presencia del infinito que disminuye y agobia y disuelve la materia en reflejos, sueños o simulacros, al hilo

${ }^{1}$ Indicamos a continuación las obras de Borges (todas publicadas en Buenos Aires) y las abreviaturas con que algunas de ellas se citan: Fervor de Bueros Aires, Imprenta Serantes, 1923; Inquisiciones (1), Luna de enfrente, El tamaño de mi esperanza (TE) y Cuaderno San Martin (CSM), Editorial Proa, 1925, 1925, 1926 y 1929; El idioma de los argentinos (IA), Evaristo Carriego (EC) y Discusion (D), M. Gleizer editor, 1928, 1930 y 1932; Historia unizersal de la infamia (HUI), Editorial Tor, 1935 (Colección Megáfono, 3); Historia de la eiernidad (HE), Viau y Zona editores, 1936; Poemas (1922-1943) (P), Editorial Losada, 1943; 2" ed. aumentada $\left(P^{*}\right)$, en Obras completas, Editorial Emecé, 1954; Fic ciones (1935-1944) (F) y Otras inquisiciones (1937-1952) (OI), Ediciones Sur, 1944 y 1952; El Aleph $(A)$, Editorial Losada, $1949 ; 2^{\circledR}$ ed. aumentada $\left(A^{2}\right), 195^{2}$.

${ }^{2}$ En $O I, 5^{6-5}$. Es un tema que le ha preocupado desde mucho antes: ya en $H E$, 102-103, cita el ejemplo de Las mil y una noches comparado con el de Hamlet; en "Cuando la ficción vive en la ficción", El Hogar, Buenos Aires, 2 de junio de 1932, agrega también Las Meninas de Velázquez, El asno de oro de Apuleyo, L'illusion comique de Corneille, Der Golem de Gustav Meyrink y At Swim-Two-Birds de Flann O'Brien; vuelve sobre ello en una nota bibliográfica de El Hogar, 28 de octubre de 1938, y en varias conferencias sobre literatura fantástica; en "Museo", Los Anales de Buenos Aires, Buenos Aires, año I, núm. 4, Pp. $53^{-56}$, publica un texto fraguado por él que atribuye a Suárez Miranda, Viajes de varones prudentes, libro IV, cap. xıv, Lérida $165^{8}$, con el mismo tema del mapa en el mapa.

"Véase el final de "Nueva refutación del tiempo" (OI, 220). 
de la filosofía idealista o de ideas religiosas o legendarias que la desintegran.

De estos temas centrales que configuran su orbe mágico, sólo analizaremos ahora la función desrealizadora del infinito a través de un estudio del vocabulario, de las metáforas, de los objetos que aparecen persistentemente con valor simbólico, de la estructura de sus relatos, de las alusiones filosóficas y literarias.

\section{LA FUNCIÓN DEL INFINITO}

Para Borges, el infinito es un concepto corruptor y desatinador de los otros, más universal y más temible que el concepto del mal $(O I, 129)$. Al mismo tiempo se siente tan atraído por él que alguna vez planeó escribir su historia, en un volumen que habría sido como el paralelo de su Historia de la eternidad. Un adelanto de esta empresa lo constituyen, sin duda, sus artículos dedicados a las paradojas de Zenón de Elea ${ }^{4}$, que son un tema capital de sus especulaciones sobre el infinito.

Además, siempre que se ha enfrentado con el funcionamiento del lenguaje y con la capacidad de los hombres de crear palabras un poco al azar, que luego se van cargando de sentido al correr de los años, surge insistentemente el ejemplo del término infinitos, como una revelación de su obsesión $(I A, 164)$ :

Sospecho que la palabra infinito fue alguna vez una insípida equivalencia de inacabado; ahora es una de las perfecciones de Dios en la teología y un discutidero en la metafísica y un énfasis popularizado en las letras y una finísima concepción renovada en las matemáticas - Russell explica la adición y multiplicación y potenciación de números cardinales infinitos y el porqué de sus dinastías casi terribles - y una verdadera intuición al mirar el cielo.

Muchos se han fijado en el intelectualismo de Borges, que califican de excesivo, y en sus condiciones de escritor que rige los relatos con rigor matemático. Pocos han visto que con ese rigor intelectual convive muy a menudo el más exaltado apasionamiento ${ }^{6}$. Por eso interesa detenerse en un texto como el anterior, donde lo vemos admirar la formulación matemática de un pensamiento metafísico. Casi diríamos que le place estéticamente la limpidez de la presentación del problema ("una finísima concepción"), pero también ve la trascendencia del misterio que encierra y su amenaza para el hom-

" "La perpetua carrera de Aquiles y la tortuga" (D, 151-161) y "Avatares de la tortuga" (OI, 129-135).

"Véase $D, 135$ y $161 ; I, 106$.

- Podría aplicársele la fórmula que él acuñó para Schopenhauer: "apasionado y lúcido". Recuérdese que Dios le otorgó para componer el Poema: "álgebra y fuego" $\left(P^{2}, 16_{5}\right)$. 
bre. Y esto último lo trasmite trasmutando la fórmula numérica en una frase apasionadamente imaginativa ("sus dinastías casi terribles"), cuya carga de emoción se remansa en la poética visión del cielo.

Borges sabe que toda realidad se disuelve con la presencia del infinito y lo convoca casi constantemente en sus obras, a veces aludiéndolo con una palabra, otras desarrollándolo en complejo argumento. A través de esa variedad de apariciones pueden distinguirse ciertas formas esenciales de imaginarlo: los vastos ámbitos espaciales y temporales, las multiplicaciones interminables, el camino sin fin (lineal y cíclico), la inmovilización en un gesto.

\section{LA VASTEDAD DEL TIEMPO Y DEL ESPACIO}

La proyección de horizontes borrosos y de metas inalcanzables contribuye a crear una atmósfera de inquietud y de ensoñación. A menudo le basta con insinuar un ámbito de amplitud desmesurada. Borges ha expresado en "La busca de Averroes" la sensación agobiadora que produce la simple mención de tales vastedades: "El temor de lo crasamente infinito, del mero espacio, de la mera materia, tocó por un instante a Averroes. Miró el simétrico jardín; se supo envejecido, inútil, irreal" ( $A, 9^{8-99)}$.

Por eso abundan en sus libros ciertos adjetivos que son como un vago ademán en el tiempo y en el espacio: vasto, remoto, infinito, enorme, desaforado, eternizado, inmortal, grandioso, desmantelado, dilatado, incesante, inagotable, insaciable, interminable, hondo, cóncaz̃o, agravado, profundo, final, último, penúltimo, lateral, perdido, desterrado, extraviado, cansado, fatigado, vertiginoso.

Vasto e infinito ${ }^{7}$ son dos de las palabras que más se repiten: hay una "vasta cámara circular" en el laberinto de los Inmortales $(A, 13)$, "una vida de vastos amaneceres" para "El muerto" $\left(A, 3_{1} 1\right)$, "un vasto fragmento metódico" de la historia de Tlön cuenta sus maravillas $(F, 18)$, el universo es vasto e incesante $(A, 125)$, vastas y errantes las representaciones teatrales que aluden al gran teatro del mundo $(F$, ${ }_{15} 8$ ). "Compleja y casi infinita" es Inglaterra (Sur, núm. 129, p. 1o); se siente "la infinita presencia de una conjuración" ( $\left.A^{2}, 192\right)$; infinito insinúa de manera indirecta la aventura del tribuno Rufo en las primeras páginas de "El inmortal" con la presencia del desierto que evoca el color de ensueño de la arena: "Me levante poco antes del alba; mis esclavos dormían, la luna tenía el color de la infinita arena" $(A, 8)$. También le sirve para estirar hasta eternizarlo el tiempo que vuelve cíclicamente: "Cuando Roma sea polvo, gemirá en la infinita / noche de su palacio fétido el minotauro" ( $P$, 164). Esta palabra

${ }^{7}$ Para vasto véase también: $P, 162 ; F, 11,68,43 ; A, 109,90,39 ; O I, 11,9$, 153. Para infinito: $A, 111,32,21,22,69,71,125 ; O I, 9,10 ; 1,81$. Para infinitud: $I, 127 ; H E, 20 ; D, 75$. 
aparece a veces con una música de milonga que se continúa largamente y que simboliza la eternidads: “. . alguien infinitamente rasguea una trabajosa milonga..." $(A, 35)$; “...un acordeón despachaba infinitamente la Cumparsita..." (OI, 190); "De la otra pieza le llegaba un rasgueo de guitarra, una suerte de pobrísimo laberinto que se enredaba y desataba infinitamente..." (Nac, 11 de octubre de 1953).

Otras variantes son: grandioso, dilatado, enorme ${ }^{9}$, desaforado. Desaforado ${ }^{10}$ es palabra que trae el aire sensacional y desbaratador de Quevedo; aunque abunda más en su primera época, se prolonga hasta las últimas obras. Así la encontramos en Ficciones: "un callejón final de tapias rosadas que parecian reflejar de algún modo la desaforada puesta de sol" (p. 166) y también El Aleph: "amanecía en la desaforada llanura" (p. 59). Borges puede haberla usado independientemente del influjo de Quevedo, pero las implicaciones de sus diferentes significados ('excesivamente grande y fuera de lo común', 'el que obra sin reparo, ley, ni fuero, atropellando por todo', 'desordenado, excesivo, desmedido') condicen con el tono fundamental de nuestro clásico.

Remoto $^{11}$ es otro epíteto que al alejar los seres los desdibuja: "constelaciones remotas" ( $P$, 98), "hombres remotos, hombres barbados y mitrados" (HE, 28), "remota cifra de vértigo" $(I A, 29)$. En un dormitorio que antes ha calificado de "desmantelado y oscuro", ya con la nota de vastedad y decadencia, "hay un remoto espejo que tiene la luna empañada" $(A, 32)$; en esta frase la resonancia de $r e$ moto, ampliada en su connotación de borrosidad por el adjetivo empañada, aparece apoyándose en un objeto, el espejo, símbolo de irrealidad y de otros varios valores que luego estudiaremos.

" Recućrdese que ha dicho de la milonga: "El tango está en el tiempo, en los desaires y contrariedades del tiempo: el chacaneo aparente de la milonga ya es de eternidad. La milonga es una de las grandes conversaciones de Buenos Aires..." (EC, 77).

" "Grandiosa y viva / como el oscuro plumazón de un ángel / que anonadase con pavor de alas el día, / la noche pierde las mediocres calles / de la ciudad hundida / en uno de los ángulos del tiempo / bajo la inmensidad vana y baldia" $(P, 60)$. - "Nadie en las dilatadas tierras que fueron suyas, dio con el laberinto" $(F, 119)$; "que al pie del claro cielo / vertiginosamente dilatado..." $(P, 46)$; "en el dilatado universo no hay dos caras iguales" $(A, 40)$. - "Juró olvidar la enorme alucinación" $(F, 69)$; "De fierro / de encorvados tirantes de enorme fierro tiene que ser la noche" $(P, \mathbf{1 6 1})$; "el período enorme revela un ejecutor sobrehumano" $(O I, 24)$; "o un solo enorme día multiplicado por el sol, por la sed..." $(A, 10)$.

10 "Se derrumbó el complejo cielo verdoso, / en desaforado abatimiento de agua y de sombra" $(P, 25)$; "Este cielo incalificable, ido, desaforado, cuyo nombre mismo quiere decir apagamiento, extinción" $\left(I A, 5^{2}\right)$; "el aire despejado de los desiertos, la desaforada pradera" (HUI, 67).

I1 "Tampoco el fondo de los años guarda / un remoto jardín" $(P, 168)$. Véanse tambićn: $A, 37 ; H E, 13 ; P, 31 ; F, 13^{1}$ y $9^{6 .}$ 
Inmortal, eternizado, perdurable se refieren a la infinitud en el tiempo, pero muy a menudo los encontramos junto a interminable, inagotable, insaciable, incesante, perdido, desterrado, extraviado, fatigado (fatigar, fatiga $)^{12}$, cansado, en expresiones que conjugan las categorías del tiempo y del espacio, aludiendo a la imposibilidad de que nuestras limitadas vidas alcancen a recorrer tales distancias, con la nota de angustia y caducidad que ello implica: "inmortales distancias" $(P, 11)$, "insaciable inmortalidad de ponientes" $(P, 110)$, "incesante y vasto universo" $(A, 125)$, "perdurable llanura" $\left(I, 13^{8}\right)$, "interminable llanura" $(A, 32)$, "laberinto... incesante" $(F, 179)$, "llanura inagotable" $(A, 31)$, "arrabal cansado" $(P, 27)$, "las fatigadas leguas incesantes del suburbio del Sur" $(P, 162)$. En las últimas formas, Borges califica el espacio con un adjetivo que en realidad se refiere a las sensaciones experimentadas por el sujeto que lo recorre.

Vertiginoso ${ }^{13}$ es también - con vasto e infinito- una de las palabras claves y puede encerrar en sí el estremecimiento de quien toca el misterio y el anuncio del milagro inminente, o la angustia del fantasma perdido en una peregrinación inacabable: en último término la emoción de quien se siente sorbido por las simas profundas del éxtasis o de la nada. "Vertiginoso silencio" lo acompaña en esa calle de Buenos Aires donde una noche intuye el sentido de la palabra eternidad $(O I, 212)$, vertiginoso es el palacio de los Inmortales, fábrica irracional que simboliza el universo $(A, 25)$, una "torre de vértigos" construye el protagonista de "El muerto" erigiendo "exultación sobre exultación, júbilo sobre júbilo" $(A, 35)$ como una nueva torre de Babel para alcanzar y suplantar a la Divinidad que ha de despeñarlo.

Una de las formas fundamentales en que Borges vio a Buenos Aires y gustó la emoción de sus barrios desde la primera época, está basada en las calles de los suburbios, de casas bajas, que se disuelven en la llanura. "Yo adjetivé alguna vez honda ciudad, pensando en esas calles largas que rebasan el horizonte y por las cuales el suburbio va empobreciéndose y desgarrándose tarde afuera..." $\left(I, 5^{8-59}\right)$. A través de diferentes textos persiste la visión conjunta de un espacio y un tiempo sin límites donde se alcanzan las notas de lo patético

12 Fatigar es quizá una de las que más se repiten: "suele visitarme en las noches y en el fatigado crepúsculo" $(O I, 203)$; "a fuerza de fatigar patios con un aljibe y polvorientas galerías" $(A, 71)$. Véanse también: $A, 94 ; P, 72,26$; $I, 127 ; A^{2}, 192$. Borges la emplea con el sentido de practicar insistentemente algo, expresión inusual que sus imitadores suelen copiar ("fatigamos largamente [la metáfora]", $I, 27$ ) junto con otra muy semejante: "sospechamos que no suele visitar la literatura" $(F, 92)$.

${ }^{13}$ Los ejemplos de vertiginoso son numerosísimos: "desierto vertiginoso", "tierras vertiginosas" (HUI, 64, 87) ; "país vertiginoso", "mundo vertiginoso", "mapa vertiginoso de la India" $(F, 76,141,188)$; "el vértigo de un teólogo, desterrado del orbe del Almagesto y extraviado en el universo copernicano" (OI, 112); "en lo vertiginoso, en lo altísimo, vi un círculo" $(A, 14)$. 
"hostilizadas", "desgarrándose”, “despedazándose”, "ponientes pavorosos como arrebatos de la carne", por la proyección inabarcable de la llanura y del cielo, junto a la angustia del transcurrir de las horas simbolizado en el ocaso"4. "He visto un arrabal infinito donde se cumple una insaciable inmortalidad de ponientes" $(P, 110)$; "callejones que son más largos que el tiempo" $(C S M, 14)^{15}$;

sino la dulce calle de arrabal

enternecida de árboles y ocaso

y aquellas más afuera

ajenas de piadosos arbolados

donde austeras casitas apenas se aventuran

hostilizadas por inmortales distancias

a entrometerse en la honda visión

hecha de gran llanura y mayor cielo $(P, 11)$.

Con esta manera de imaginarse la ciudad se enlaza el valor de ciertas palabras: hondo, profundo, agravado, cóncavo, hueco ${ }^{18}$, que trabajan las metáforas de lo inmenso en términos de profundidad, ya aplicadas a Buenos Aires, ya a descripciones de laberintos o a una fusión de ambos.

Las plazas agravadas por la noche sin dueño

son los patios profundos de un árido palacio

y las calles unánimes que engendran el espacio

son corredores de vago miedo y de sueño $\left(P, 16_{5}\right)$.

"La honda noche universal", dice en "Amanecer" $(P, 43)$.

Arrabal (en pocos casos orillas) trae una connotación de bordes de vivir, de borrosas regiones remotas que además de ser los barrios extremos de la ciudad, pueden ser también los "arrabales del alma" 17 y "los arrabales desmantelados del mundo" ( $P, 49)$. Borges suele unirles un tipo de adjetivación especial: últimos, penúltimos, laterales, finales ${ }^{18}$, casi con velada alusión a la región infernal:

14 En muchos pasajes de su obra explica esta emoción que suscitan en él la Ilanura o el arrabal que se disuelve en la pampa, iluminados por el sol poniente, donde se mezclan la sensación del infinito espacial y la angustia de lo temporal. Véase especialmente $1,81,98$.

15 "Las encrucijadas oscuras que alancean cuatro infinitas distancias" ( $P$, $\left.6_{5}\right)$; “calles que surcan las leguas como un vuelo" $(P, 116)$; "calles... largas como la espera" $(I, 83)$; "palabra [orillas]... que da a Ias afueras su aventura infinita" ( $P, 117)$; "Hacia los cuatro puntos cardinales / se han desplegado como banderas las calles" $(P, 12)$.

16 "y una honda ciudad ciega / de hombres que no te vieron" $(P, 62)$; "En la honda noche universal" $(P, 42)$; "hondas escaleras de vértigo" $(F, 152)$. "Vuelve la noche cóncava que descifró Anaxágoras" $(P, 166)$; "En Villa Ortúzar... hay unos huecos hondos" (CSM, 19); "militará en la hondura de la calle" $(P, 39)$.

iz El verso de "La Recoleta" en el que figuraba esta expresión (Fervor de Buenos Aires) fue suprimido por Borges al recoger sus poesías en Poemas.

18 "el barrio era una esquina final" $(E C, 25)$; "Chacarita: / desaguadero 
Sin esperanza ni temor, perdido,

huyo hacia el Sur, por arrabales últimos $(P, 170)$.

Formas del vacío ahondan los barrios en sus primeros libros, con imágenes y hasta con palabras que recuerdan a Lugones, al ValleInclán más grave y goyesco y, más lejos, a Quevedo: “ese casi infinito flanco de soledad que se acavernaba hace poco" $(E C, 23)$; en Villa Ortúzar "hay unos huecos hondos" (CSM, 19); "arrabal son esos huecos barrios vacíos en que suele desordenarse Buenos Aires por el oeste" $(I A, 165)$.

Los últimos ensayos y los cuentos nos asombran con la variedad de metáforas y de temas que aluden al infinito. Encontramos los grandes ciclos temporales concretados, a menudo, en la persistencia de una actitud desde que la luz aparece hasta que se acaba: "Lo recuerdo... con una oscura pasionaria en la mano, viéndola como nadie la ha visto, aunque la mirara desde el crepúsculo del día hasta el de la noche, toda una vida entera" $(F, 131)$. O proyectados hacia un pasado remotísimo de expresión gradualmente intensificada: "Antes que ningún otro rasgo de ese monumento increíble, me suspendió lo antiquísimo de su fábrica. Sentí que era anterior a los hombres, anterior a la tierra" $(A, 14)^{19}$.

También rodean a los personajes los amplios ámbitos geográficos: "Buscó los arduos límites del imperio, las torpes ciénagas y los contemplativos desiertos, para que lo ayudara la soledad a entender su destino. En una celda mauritana, en la noche cargada de leones..." $(A, 47)$. La India, especialmente, le sirve de metáfora del universo, con su doble alusión a lo vasto y a lo caótico. En $D, 119$, hablaba ya de "el asiático desorden del mundo real" y en $A^{2}, 132$, recuerda el proverbio que afirma que la India es más grande que el mundo. Por eso y porque las creencias religiosas y filosóficas, la tradición de literatura fantástica, y su relativa imprecisión para los occidentales le permiten alojar en ella cualquier irrealidad (véase $A^{2}$, 157), la elige como asiento mítico de algunos de sus cuentos. Es indudable que "una peregrinación que comprende la vasta geo-

de esta patria de Buenos Aires, cuesta final" ( $P, 141)$; "la noche lateral de los pantanos" (P, 171); "noche lateral de los callejones" (EC, 25); "campos medanosos y últimos y húmedos" (TE, 87); "Palermo era una esquina última y arriesgada" (Nosotros, Buenos Aires, año 20, núm. 210, p. 322); "Busca los arrabales últimos" $(F, 41)$; "El revés de lo desconocido, su espalda, son para mí esas calles penúltimas" (OI, 211).

1. "Esas cosas ocurrieron y se olvidaron hace ya muchos años" $\left(A^{2}, 137\right)$. En "El Sur" (Nac, 8 de febrero de 1953), Borges repite con las mismas palabras la descripción del anciano protagonista de "El hombre en el umbral" y agrega otras frases para acentuar el efecto de lo infinito temporal: "se acurrucaba, inmóvil como una cosa, un hombre muy viejo. Los muchos años lo habían reducido y pulido como las aguas a una piedra o las generaciones de los hombres a una sentencia. Era oscuro, chico y reseco, y estaba como fuera del tiempo en una eternidad". 
grafía del Indostán" $(F, 43)$ es el escenario adecuado para las interminables postergaciones de "El acercamiento a Almotásim". Así comprendemos que Hladík encuentre a Dios y a la revelación de "El milagro secreto" en un vertiginoso mapa de la India $(F, 188)$, porque ese mapa encierra, como la biblioteca total, las formas posibles que abarca la mente de Dios y además su clave todopoderosa.

Las inmensidades pueden exaltar en lugar de disminuir, si a ellas se une la emoción de la aventura. Ese sentido tiene en la obra de Borges la frontera del Brasil y del Uruguay ${ }^{20}$. Tanto él como otros compañeros de generación (Amorim, Ipuche) pensaron que el litoral y el Uruguay son más elementales que la pampa argentina y que la esencia de lo criollo se conserva en esas regiones más puro. El mismo amor al peligro que le hizo fijarse en la figura del compadrito ${ }^{21}$, lo llevó a buscar en Entre Ríos, el Uruguay y la zona fronteriza del Brasil el mítico lugar del coraje y la plenitud de la vida. De esa misteriosa zona procede el hombre que trae a la tierra objetos del universo ficticio de Tlön $(F, 34)$; también de allí viene Azevedo Bandeira $(A, 32)$, el contrabandista que es una rústica encarnación de Dios; y en su propio Juicio final, cita entre las riquezas que inútilmente le otorgó el Señor para alcanzar el poema: "fronteras del Brasil y del Uruguay, caballos y mañanas" 22 .

Enumeraciones acumulativas de selvas, ríos, ciudades, cordilleras (enumeraciones mezcladas unas veces sí y otras no con las emociones humanas) pueden servir para expresar el júbilo o la desesperanza al ofrecer la posesión de un universo múltiple e inabarcable, que por serlo admite las dos opuestas tendencias del rapto, si se cree conseguirlo, y de la desesperación, si se fracasa. "Negar la eternidad, suponer la vasta aniquilación de los años cargados de ciudades, de ríos y de júbilos no es menos increíble que imaginar su total salvamento" (HE, 29).

Del temple emocional de los elementos elegidos dependerá el efecto que consiga. Para Azevedo Bandeira, divinidad cruel que condena al hombre desde la eternidad dejándole la’patética ilusión de creerse libre, conviene la resonancia de una infinitud de poder misterioso y de monstruosidad ${ }^{23}$ : "Alguien opina que Bandeira nació del otro lado del Cuareim, en Río Grande do Sul; eso que debería

${ }_{20}$ "En lo que Tabares dijo y no dijo percibí el agreste sabor de lo que se llamaba artiguismo: la conciencia (tal vez incontrovertible) de que el Uruguay es más elemental que nuestro país, y por ende, más bravo..." $(A, 76)$.

${ }^{21}$ Para el deseo de aventuras que sintió su generación, cf. Aspectos de la literatura gauchesca, ed. de Número, Montevideo, $195^{\circ}$.

${ }^{22}$ Véase el poema "Mateo XXV, 30", en Nac, ${ }_{15}$ de noviembre de 1953 , recogido en $P^{2}, 16_{5}$.

${ }_{23}$ Selvas, ciénagas y pantanos traen también en otros textos las notas de lo monstruoso y caótico: “...lo envió al otro templo cuyos despojos blanquean río abajo, a muchas leguas de inextricable selva y de ciénaga" $(F, 71)$; "A través de una oscura geografía de selvas y ciénagas" $\left(A, 5^{\mathbf{0}}\right)$. 
rebajarlo, oscuramente lo enriquece de selvas populosas, de ciénagas, de inextricables y casi infinitas distancias" $(A, 32)$. Para la vigilia de "Insomnio" convienen las inmensidades desanimadas de sórdidos arrabales, de llanuras de barro y de basura. Si las cosas concretas -ciénagas, selvas- son metáforas de caracteres morales y de sentimientos, inversamente ocurre que los calificativos éticos y emocionales se aplican a los objetos físicos: "barro torpe", "pampa basurera y obscena" $(P, 162)$.

Ya al considerar ciertos tipos de adjetivación ("inmortales distancias"; y en el texto citado unas líneas más arriba, "años cargados de ciudades..."), se nos ha presentado una característica constante de la obra de Borges: la unión de la inmensidad espacial y temporal en ricas implicaciones ${ }^{24}$. Esta relación puede manifestarse enlazando en un mismo plano tiempo y espacio ("incesante y vasto universo") o subordinando una categoría a la otra, es decir, aplicando a un núcleo espacial una modificación temporal o viceversa ("fatigadas leguas incesantes", $P, 162$; "callejones que son más largos que el tiempo", $C S M, 14)$.

Muy claramente se nota su gusto por las asociaciones espaciotemporales cuando trata uno de sus temas favoritos, el sentido secreto del universo manifestado en el enlace de hechos aparentemente inconexos. Entonces las épocas y tierras apartadas apuntan al milagro de ese enlace y realzan su misterio con la proyección de la infinitud. La simetría de los sueños de Kubla Khan, que "abarca continentes y siglos", está trabajada mágicamente en los dos ámbitos pero sobre todo en la línea de la magnitud temporal, para preparar el camino de la revelación $(O I, 23-25)$ :

Hay, sin embargo, un hecho ulterior, que magnifica hasta lo insondable la maravilla del sueño en que se engendró Kubla Khan. Si este hecho es verdadero, la historia del sueño de Coleridge es anterior en muchos siglos a Coleridge y no ha tocado aún a su fin... Si no marra el esquema, algún lector de Kublai Khan soñará, en una noche de la que nos separan los siglos, un mármol o una música. Ese hombre no sabrá que otros dos soñaron. Quizá la serie de los sueños no tenga fin, quizá la clave esté en el último.

En cambio, "El enigma de Edward Fitzgerald" atiende por igual a destacar la lejanía de los países y de las épocas, para mostrar la engañosa desconexión de los hechos mientras los va relatando en su sucederse y los secretos hilos que los unían, sólo visibles al final:

Un hombre, Umar ben Ibrahim, nace en Persia, en el siglo XI de la era cristiana... Muere [un día del año $5^{17}$ de la Héjira], a la hora de la puesta del sol. Por aquellos años, en una isla occidental

${ }_{24}$ "Mil trescientos años y el mar median entre el destino de la cautiva y el destino de Droctfult" ( $A, 54)$; "a muchos siglos de distancia y a una altura estelar" $(F, 67)$. 
y boreal que los cartógrafos del Islam desconocen, un rey sajón que ha derrotado a un rey de Noruega es derrotado por un duque normando.

Siete siglos transcurren, con sus luces y agonías y mutaciones, y en Inglaterra nace un hombre, Fitzgerald, menos intelectual que Umar, pero acaso más sensible y más triste (OI, 91-92).

También el ensayo acerca del emperador Shih Huang Ti que mandó construir la muralla china y quemar los libros anteriores a él, está planeado sobre la interpretación simbólica de dos hechos que toman parte de su prestigio de la inmensidad espacial y temporal. $\mathrm{Y}$ aún resulta más revelador ver cómo Borges expresa el símbolo espacial - la muralla- en términos entretejidos de tiempo que se agrandan prodigiosamente hasta incluirlo a él mismo, y a nosotros con él, en un abrazo que abarca la eternidad: "La muralla tenaz que en este momento, y en todos, proyecta sobre tierras que no veré, su sistema de sombras..." (OI, 11).

El efecto desrealizador y patético que ejerce la presencia de este doble infinito espacio-temporal suele acentuarse con el relato de hechos o con la superposición de imágenes en círculos concéntricos cada vez más vastos, incluidos unos dentro de otros ${ }^{25}$. Muy a menudo parte de un sitio o de un momento precisos, y en ondas que se amplían rebasa el lugar y la época hasta comprehender el universo y la eternidad. La representación planeada para castigar a Kilpatrick en el "Tema del traidor y del héroe", cuento basado en el viejo topos del teatro del mundo, se multiplica y se extiende. "Kilpatrick fue ultimado en un teatro, pero de teatro hizo también la entera ciudad, y los actores fueron legión, y el drama coronado por su muerte abarcó muchos días y muchas noches" $\left(F,{ }_{15} 8\right)$. Así decía en la primera versión del cuento publicada en Sur, núm. 112 , pp. 23-26. No satisfecho con esto, Borges agregó un párrafo final que prolonga la representación teatral prevista por Nolan-Dios al hombre que años más tarde investiga la historia y a un futuro sin término $(F, 160)$. Quizás la más poética y eficaz de estas oleadas crecientes de espacio y tiempo fundidos sea la de "El jardín de senderos que se bifurcan", cuando Yu Tsun, perdido en el laberinto de su destino, piensa en el laberinto creado por su antepasado Ts'ui Pên:

Bajo los árboles ingleses medité en ese laberinto perdido: lo imaginé inviolado y perfecto en la cumbre secreta de una montaña, lo imaginé borrado por arrozales o debajo del agua, lo imaginé

25 "... algo en la carne de Averroes, cuyos antepasados procedian de los desiertos árabes, agradecia la constancia del agua. Abajo estaban los jardines, la huerta; abajo, el atareado Guadalquivir y después la querida ciudad de Córdoba... y alrededor (esto Averroes lo sentía también) se dilataba hacia el confín la tierra de España, en la que hay pocas cosas, pero donde cada una parece estar de un modo sustantivo y eterno" ( $A, 93-94)$. 
infinito, no ya de quioscos ochavados y de sendas que vuelven, sino de ríos y provincias y reinos... Pensé en un laberinto de laberintos, en un sinuoso laberinto creciente que abarcara el pasado y el porvenir y que implicara de algún modo los astros $\left(F, 115^{-116}\right)$.

El horror de la ciudad de los Inmortales se lanza a un ámbito universal con palabras semejantes, acentuado por el contraste de los extremos: la ciudad oculta en el centro de un desierto y su acción sobre una amplitud que llega a los cielos y comprende las dos direcciones del tiempo: "Esta ciudad (pensé) es tan horrible ${ }^{26}$ que su mera existencia y perduración, aunque en el centro de un desierto secreto, contamina el pasado y el porvenir y de algún modo compromete a los astros. Mientras perdure, nadie en el mundo podrá ser valeroso o feliz" $(A, 16)$.

Tan significativa es esta construcción y tan propia de la forma de imaginación de Borges, que en su prólogo a Artificios ( $F, 129$ ) dice que después de redactar "La muerte y la brújula" pensó habría podido ampliarse la duración de la venganza a años o a siglos, y los vértices de su figura a Islandia, México, Indostán y Buenos Aires.

\section{LAS MULTIPLICACIONES INFINITAS}

Otra visión del infinito característica de la obra de Borges es la multiplicación interminable que puede presentarse para alucinarnos en la discusión de una teoría cosmológica o filosófica, en la estructura de un cuento, en un detalle descriptivo, en una metáfora preferida, en un vocabulario que abunda en las manifestaciones de lo múltiple.

A Borges le interesa Pascal porque lo ve perdido en un tiempo y en un espacio ilimitados $(O I, 16,112-113)$ y además enloquecidamente reflejado en orbes que proliferan y se incluyen como las muñecas rusas $^{27}$. Lo verdaderamente patético reside en que Pascal tenga

${ }^{20}$ En la concepción del horror que inspira la ciudad de los Inmortales, como en las expresiones "pampa obscena", "agua crapulosa", parecen haber influido sus lecturas de algunos autores ingleses: Chesterton, El hombre que fue jueves, 6 (una torre "cuya sola arquitectura es malvada"); Stevenson, $A$ Chapter on dreams ("matiz abominable del color pardo"), citado por él en $O I, 162$. También MAY Sinclair, "Donde su fuego nunca se apaga" ("Dobló por otro corredor que era oscuro, secreto y depravado"), recogido en Antologia de la literatura fantástica, p. 248. Para oposición centro-infinito, compárese: "Desde el invisible horizonte / y desde el centro de mi ser una voz infinita / dijo estas cosas..." $\left(P^{2}, 16_{4}\right)$.

${ }^{27}$ Sobre la pluralidad de mundos Borges cita a Demócrito y el comentario que de sus ideas hace Cicerón (Cuestiones académicas, libro 2, 40) en $P, 175$ y $A, 3^{8}$, donde también recuerda a Plutarco: "Esa noche, Aureliano pasó las hojas del antiguo diálogo de Plutarco sobre la cesación de los oráculos; en el párrafo veintinueve, leyó una burla contra los estoicos que defienden un infinito ciclo de mundos, con infinitos soles, lunas, Apolos, Dianas y Poseidones". Cf. también $O I, 115$. 
conciencia de su soledad, se sienta él mismo perdido y se vea él mismo en los espejos sin cuento, diminutos o inmensos, de universos que contienen a otros universos, de átomos que contienen a otros átomos $(O I, 115)$. La misma construcción mental abarrotada "de mundos facsimilares y de mundos disímiles" $(P, 175)$ o poblada de tiempos en los que se sitúan los sujetos del interminable $r e$ gressus hace que se fije en autores secundarios como Dunne y Blanqui (OI, 27 ss.) o en la cosmogonía de Basílides con sus orbes sucesivos como reflejados en espejos $(D, 81)$.

Borges ha incorporado también a sus cuentos la idea de un tiempo que se ramifica indefinidamente. Resalta entonces su peculiaridad, cuando se advierte que en una época de tanta difusión de las doctrinas existencialistas, él no se detiene en la angustia de la elección ni en la mutilación que implica, sino que prefiere otros rumbos. Su fantasía prolifera en infinitos caminos que divergen, corren paralelos o se entrecruzan porque juega con la posibilidad de elegir todos los destinos y de ir viviendo infinitas historias infinitamente ramificadas"s. El "Examen de la obra de Herbert Quain" y "El jardín de senderos que se bifurcan" contienen la descripción de novelas con argumentos bifurcados, pero es grande el contraste del tono entre los dos. En el primer relato Borges presenta la novela separada del mundo que figura ser real, la resume en una fórmula matemática fría e impersonal, con la burla clasificadora de los argumentos en simbólicos, psicológicos, policiales o comunistas, y la ironía de intercalar su autocrítica dentro del relato: "De esta estructura cabe repetir lo que declaró Schopenhauer de las doce categorías kantianas: todo lo sacrifica a un furor simétrico" $(F, 91)$. En el segundo caso la ficción desborda su recinto y contagia a la supuesta realidad que se vuelve tan caótica y extraña como ella. El ingenioso cuento policial se profundiza, una atmósfera inquietante lo invade y lo convierte en el símbolo de nuestro destino de hombres perdidos en el universo. Mientras un laberinto ${ }^{29}$ de espacio y tiempo -otro símbolo del infinito y del caos- rodea al protagonista, éste se ve inmerso en un mundo rebosante de sus imágenes y de las de su víctima, que se mueven y se multiplican $\sin f i n(F, 122-123,125)$ :

${ }^{28}$ En la Antología de la literatura fantástica, publicó Borges este pasaje del Star Maker de Olaf Stapledon sobre la multiplicidad de destinos: "En un cosmos inconcebiblemente complejo, cada vez que una criatura se enfrentaba con diversas alternativas, no elegía una sino todas, creando de este modo muchas historias universales del cosmos". En $A$, 80, copia la expresión final, aplicándola a las consecuencias de que Dios cambie el pasado.

${ }^{29}$ No nos detendremos ahora en el valor del laberinto, porque lo estudiamos con detalle en otro trabajo dedicado al caos y al cosmos en la obra de Borges. Para la idea del universo como un caos, cf. Paul Bénichou, "Le monde et l'esprit chez Jorge Luis Borges", Les Lettres Nouvelles (Paris), II (1954), $680-699$ 
Desde ese instante, sentí a mi alrededor y en mi oscuro cuerpo una invisible, intangible pululación. No la pululación de los divergentes, paralelos y finalmente coalescentes ejércitos, sino una agitación más inaccesible, más íntima y que ellos de algún modo prefiguraban...

Volví a sentir esa pululación de que hablé. Me pareció que el húmedo jardín que rodeaba la casa estaba saturado hasta lo infinito de invisibles personas. Esas personas eran Albert y yo, secretos, atareados y multilormes en otras dimensiones de tiempo.

La misma manera de captar el infinito se repite cuando se trata de las aporías eleáticas, porque Borges traduce la interminable subdivisión del tiempo y del espacio en miles de seres y en miles de abismos donde ellos se despeñan $\left(D, 154^{-1} 55\right)$. Ante la paradoja de Aquiles y la tortuga siente el estremecimiento por el misterio que se entrevé y el placer estético por la belleza de la formulación ${ }^{30}$; y halla esa belleza en la metáfora que Zenón de Elea acuñó, por la aventura que promete y que él desenvuelve imaginativamente en una perpetua persecución de seres que disminuyen o se agrandan monstruosamente, o en angustiosas caídas en precipicios oníricos. o en "tenues laberintos de tiempo" $(O I, 134)$. Pero también encuentra el mismo valor estético en las límpidas formulaciones matemáticas: en la serie de los números $10+1+\frac{1}{10}+\frac{1}{100} \cdots+\frac{1}{00}$, en la refutación de Bertrand Russell o en la explicación de William James.

El final de "La muerte y la brújula" une la forma dramática de la venganza y la persecución con la simplicidad del dibujo geométrico: el esquema de Zenón de Elea que Lömrot propone para que lo maten en una vida futura, es simple como una línea recta pero patético por la posibilidad de perderse en él como en un desierto $(F, 179)$.

La carrera de Aquiles y la tortuga no es sólo un elemento que contagia de irrealidad los cuentos. La razón de su sinrazón corona el ensayo que Borges le dedica en Otras inquisiciones donde, con el poder de elevar a potencias incalculables las fantasmagorías, acaba por presentarla como el instrumento que conscientemente hemos creado para revelar la verdadera naturaleza de un orbe de ensueño.

Admitimos lo que todos los idealistas admiten: el carácter alucinatorio del mundo. Hagamos lo que ningún idealista ha hecho: busquemos irrealidades que confirmen ese carácter. Las hallaremos, creo, en las antinomias de Kant y en la dialéctica de Zenón.

"El mayor hechicero (escribe memorablemente Novalis) seria el

3o "El problema no cambia, como se ve; pero me gustaría conocer el nombre del poeta que lo dotó de un héroe y de una tortuga" (OI, 19o), dice, destacando el goce literario que le produce, y luego vuelve a afirmar un juicio estético sobre la formulación de la misma idea por William James: "Un ejemplo final, quizá el más elegante de todos". Véase igual actitud en $D,{ }_{15}^{1}, 157$. 
que se hechizara hasta el punto de tomar sus propias fantasmagorias por apariciones autónomas. ¿№ seria ése nuestro caso?" Yo conjeturo que así es. Nosotros (la indivisa divinidad que opera en nosotros) hemos soñado el mundo. Lo hemos soñado resistente, misterioso, visible, ubicuo en el espacio y firme en el tiempo, pero hemos consentido en su arquitectura tenues y eternos intersticios de sinrazón para saber que es falso $(O I, 135)$.

La estructura misma de los relatos puede aludir a la multiplicidad, bajo las formas de la inclusión, de los reflejos y de la bifurcación, complicada a veces con la repetición cíclica.

Si le atraen las obras de los demás porque el mapa de Inglaterra está dentro de Inglaterra como en Josiah Royce, la representación teatral dentro del drama como en Hamlet, los cuentos dentro de los cuentos como en Las mil y una noches (OI, 58; HE, 103), Borges construirá ficciones con esas características. La historia de Tiön es el intento de introducir en la tierra un mundo imaginado por un grupo de hombres, hasta que, a fuerza de pensarlo, el orbe fantástico adquiere consistencia y envía a la tierra objetos de materia extraña como una brújula y un cono de metal. En ese orbe fantástico que asciende a real, el autor intercala un segundo plano de irrealidad que quiere a su vez ascender a forma concreta con respecto a él: el de la duplicación de hrönir $(F, 28-30)$. Así se realiza en Tlön el curioso experimento de producir objetos (una máscara antigua, una estatua mutilada) a fuerza de desear su aparición. Cuento con estructura de caja china: mundos irreales incluídos uno dentro del otro y dentro a su vez de esta tierra que se desintegra al contacto de tales fantasmagorías.

También "El milagro secreto" encierra el relato simbólico dentro del relato. Dios concede al protagonista para que acabe su obra un año de existencia ante el pelotón que va a ajusticiarlo, año que transcurre entre la orden de fuego y la ejecución de la orden. Hladík termina entonces un drama que es en esencia el drama de su muerte: la tragedia de un hombre angustiado durante tres actos por intrigas que ocurren (que no ocurren) en un instante del tiempo histórico entre el sonar de las campanadas que abren y cierran la obra, iluminadas por el mismo ocaso $(F, 186)$. Además, Hladík es autor de otro libro, Vindicación de la eternidad, atormentado por el problema del tiempo como el cuento en que se halla inserto.

Pero varias repeticiones enloquecedoras pueblan el relato. Estando en la cárcel, el protagonista imagina una y otra vez las circunstancias de su ejecución: "absurdamente procuraba agotar todas las variaciones. Anticipaba infinitamente el proceso, desde el insomne amanecer hasta la misteriosa descarga. Antes del día prefijado... murió centenares de muertes, en patios cuyas formas y cuyos ángulos fatigaban la geometría, ametrallado por soldados va- 
riables, en número cambiante... cada simulacro duraba unos pocos segundos; cerrado el círculo, Jaromir interminablemente volvía a las trémulas vísperas de su muerte" $(F, 183)$. Los sueños agregan su nota fantasmal: el sueño inicial de la partida de ajedrez, el de la biblioteca donde Dios le revela que ha sido escuchado, y, dentro del drama Los enemigos $(F, 186)$, la impresión de lo ya visto quizá en un sueño, todo para sugerir también la posible naturaleza alucinatoria del milagro. Plano de la vida, plano de la ficción literaria, plano del sueño, plano de la alucinación, plano de lo sobrenatural y divino implicados hasta que al fin nos preguntemos sobre nuestra propia condición de seres reales o de sombras.

Los sueños con estructura de cajas chinas cumplen en la economía de su obra el papel de borrar los límites de la realidad y de crear una atmósfera de angustia. El sacerdote de Qaholom $(A, 121)$ o el mismo autor $(D, 137)$ despiertan vanamente de un sueño a otro sueño, encerrados en pirámides de pesadillas superpuestas.

Siguiendo el modelo del mapa de Inglaterra, la visión maravillosa del universo concentrada en el Aleph debe incluir en sí la cadena eterna: el Aleph en la tierra y la tierra en el Aleph $(A, 14 \mathbf{1})$. Pero además, con su costumbre de presentar en el mismo relato un tema o esquema imaginativo que le interesa, repetido con variaciones, también vemos en el Aleph otro orbe que prolifera en reflejos enloquecidos: "un globo terráqueo entre dos espejos que lo multiplican $\sin$ fin" $(A, 140)$.

Los espejos enfrentados son quizá su expresión más típica de la pluralidad de los límites. En Tlön rige la sentencia de carácter gnóstico que repudia la cópula y los espejos porque multiplican a los hombres $(F, 12,13)$; "La biblioteca de Babel", entre los muchos símbolos que sugieren la infinitud del cosmos, tiene espejos cuyas "superficies bruñidas figuran y prometen el infinito" $(F, 96)$. Dios le concedió para alcanzar la poesía, entre miles de dádivas, "sombra que olvida, atareados espejos que multiplican" $\left(P^{2}, 164\right)$. En la quinta de Triste-le-Roy, el protagonista de "La muerte y la brújula" se ve infinitamente multiplicado por espejos opuestos $(F, 173)$ mientras lo acecha la muerte; y además toda la casa es un laberinto de simetrías que el autor ha concebido pensando en la visión duph. cadora del espejo. Esa monstruosidad de los cristales que tanto le inquieta, Borges la extiende después, con su capacidad para contaminar zonas cada vez más profundas, a la naturaleza humana y al destino del hombre: "me arrasaba la fiebre, el odioso Jano bifronte que mira los ocasos y las auroras daba horror a mi ensueño y a mi vigilia. Llegué a abominar de mi cuerpo, llegué a sentir que dos ojos, dos manos, dos pulmones, son tan monstruosos como dos caras... En esas noches yo juré por el Dios que ve con dos caras y por todos los dioses de la fiebre y de los espejos tejer un laberinto 
en torno del hombre que había encarcelado a mi hermano. Lo he tejido y es firme..." (175).

Monstruosidades, repeticiones, irrealidad, evoca también la metáfora de los espejos aplicada a la Trinidad $^{31}$, a la visión del sórdido Paseo de Julio $(P, 148 ; A, 164)$, prefigurador del infierno, a los arquetipos platónicos $(H E, 16)$.

$\mathrm{Su}$ poema "Insomnio" combina las dos formas generales del infinito que hemos analizado - las repeticiones, los ámbitos vastos- y, partiendo de la pululación de imágenes de su cuerpo, acaba proyectándose hacia el remoto horizonte de la llanura, con una fórmula que conjuga la vastedad y la precisión:

En vano quiero distraerme del cuerpo y del desvelo de un espejo incesante que lo prodiga y que lo acecha y de la casa que repite sus patios y del mundo que sigue hasta un despedazado arrabal de callejones donde el viento se cansa y de barro torpe.

Las fatigadas leguas incesantes del suburbio del Sur leguas de pampa basurera y obscena, leguas de execración, no se quieren ir del recuerdo $(P, 162)$.

La misma unión de lo múltiple detallado y lo inmenso se encuentra a veces expresada por dos simples adjetivos: “CCómo no someterse a Tlön, a la minuciosa y vasta evidencia de un planeta ordenado?" $\left(F, 3^{6}\right)$.

Citaremos un último pasaje de Discusión donde puede notarse cómo ve Borges la pluralidad misma en círculos cada vez más amplios de tiempo y espacio fundidos. Aquí los proyecta, con la fórmula de los espejos enfrentados, en los dos sentidos de lo diminuto y de lo inconmensurable:

Todo eso está simbolizado en las muñecas rusas o generaciones de muñecas rusas, encerradas cada una en el vientre de la anterior y cada vez más elementales, como si la distancia del pasado y de la futuridad fuera reduciéndolas, y como si además de las seis o siete visibles hubiera incalculables otras, algunas imperceptibles de chicas, otras de gigantescas: ya recónditas de enormidad $(D, 55)$.

Una serie de adjetivos, de nombres colectivos y de verbos intensifican el modo de concebir la realidad que hormiguea en todas las direcciones del tiempo y del espacio sin límites.

En Inquisiciones, donde la influencia del estilo de Quevedo es mayor, Borges pasa revista a los procedimientos utilizados para

81. "El infierno es una mera violencia física, pero las tres inextricables personas importan un horror intelectual, una infinitud ahogada, especiosa, como de contrarios espejos". Texto repetido en $H E$, 20 y $D, 75$. 
crear imágenes y entre ellas cita las que engrandecen una cosa simple presentándola multiplicada (p. 74). Aunque no sean exclusivas de Quevedo ${ }^{32}$, es seguro que él y quizás más aún Villarroel, en quien las características del maestro se acentúan y se hacen evidentes, le enseñaron la fórmula: "Siempre, la multitud de tu hermosura" $(P, 62)$. Muchedumbre ${ }^{33}$, multitud, chusma, caterva, conventillo, montonera, aparecen especialmente en la primera época, unas veces para pluralizar un objeto singular, otras sólo para acumular individuos en un nombre colectivo, con cierta connotación de desorden y pululación de vida o de muerte. Chusma, conventillo ${ }^{34}$, montonera tienen la misma resonancia desgarrada y quevedesca del hampa o de las clases bajas, las dos últimas con el acento criollo que entonces buscaba nuestro autor. Más adelante las abandona y en cambio desenvuelve otras que expresan la multiplicidad del universo, precisa por el detalle, vaga y desrealizadora por la amplitud y la imposibilidad de abarcarla: llena, abarrotada (abarrotar), repleta, saturada, cargada, donde la realidad parece estallar incapaz de contener tal riqueza de seres. Blanqui "abarrota de mundos... no sólo el tiempo sino el interminable espacio también" $(P, 175)$; "Manuales, antologías, resúmenes... abarrotaron y siguen abarrotando la tierra" $(F, 35)$; el jardín está "saturado hasta lo infinito de invisibles personas" $(F, 125)$; hay una "mañana llena / de pasos y de sombras" $\left(P, 5^{2}\right)$; los años están "cargados de ciudades, de ríos..." (HE, 29).

A éstas se agregan: copioso, abundoso, rico, caudaloso, atareado, minucioso, numeroso, innumerable, prodigar, cundir. "La eternidad es una más copiosa invención" ( $H E$, 29); "En vano te hemos prodigado el océano, en vano el sol" $\left(P^{2}, 16_{5}\right)$; "rumor atareado de

82 Borges da en el artículo citado un ejemplo de Villarroel: "Me arremetió el tropel de un borracho"; también Villarroel habla de "una borrachera ramillete". En Quevedo, La hora de todos y la fortuna con seso (BAAEE, t. 23), se lee: "Un letrado bien frondoso de mejillas", un tabernero "diluvio de la sed", "la dueña, hecha un infierno, chorreando pantasmas" (pp. 393, 394, 389). También habla de "piaras de númenes", "bocanadas de acreedores", "cáfilas", "manada", "rebaño", "racimo", "escuadrón" (pp. 385, 39o, 393, 395, 420).

ss "disolver en su muchedumbre" $(I A, 29)$; "el culteranismo es único escándalo y se le agradace el gentío" (IA, 69); "Sea lo que fuere, la multitud de Pirandello está en Buenos Aires" [se refiere a la llegada del autor] (Sintesis, Buenos Aires, núm. 2, p. 116); "toda la charra multitud de un poniente" $(P, 69)$; "hay caterva de ángeles" (TE, 64; HUI, 93); "qué caterva de cielos" $(P, 38)$.

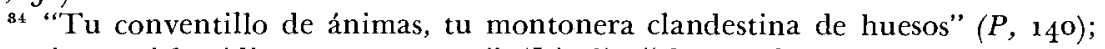
"su aire enciclopédico y montonero" $(I A, 8)$; "chusma brumosa de chimeneas atareadas" ( $I, 80)$; "Todo ello se perdió como la tribu de un poniente se pierde" ( $P, 82)$. En "Cuentos del Turquestán" (La Prensa, Buenos Aires, 29 de agosto de 1926) usa la palabra temeridad, que procede de la literatura gauchesca, en una construcción semejante a las anteriores: "ha de haber una temeridad de "yin» en Palermo Chico o en Puente Alsina". 
la lluvia" $(A, 19)$, "atareados espejos que multiplican" $\left(P^{2},{ }_{164}\right)$; "la numerosa urbe" $(P, 44)$, "el numeroso arremeter de las profundas tacuaras" $(P, 82)$; "Buenos Aires innumerable" $(I, 8)$; "minuciosa deshonra" ( $A, 53)$, "un tiempo caudaloso / donde todo soñar halla cabida" $(P, 60)$, "caudal de noches y días" $(P, 35)$; "no menos abundosa de voluntades, de ternuras, de imprecisiones" $(D, 27)$.

Pero las palabras que podríamos llamar claves, dentro de este grupo, son pululación (pulular), populoso y el mismo vertiginoso antes señalado. "Sentí... una invisible, intangible pululación. No la pululación de los divergentes, paralelos y finalmente coalescentes ejércitos..." ( $F, 122)$; "un cuerpo en el que pulularan monstruosamente, conjugados y odiándose, dientes, órganos y cabezas" $(A, 16)$; “días más populosos que Balzac" ( $\left.P^{2}, 165\right)$; "populoso mar" $(A, 139)$, "sueño populoso" $(D, 137)$, "mañana populosa" $(I A, 104)$.

La abundancia se combina con el movimiento y el desorden, asociando las emociones violentas y los sonidos: "noche de tumulto y de júbilo" $(A, 30)$, "fluye clamorosa la noche" $(A, 25)$. En $D, 137$, recuerda "un sueño populoso de cataclismos y de tumultos" y en otras obras insiste en la metáfora de un sueño intensamente cargado de seres: la soledad o la ciudad "repleta como un sueño" ( $P$, $\left.71,5^{2}\right)$ y el mundo que es "un populoso ensueño colectivo" $(P, 43)$. El cuento "Funes el memorioso", que Borges califica de larga metáfora del insomnio $(F, 129)$, desarrolla la misma sensación opresiva de la presencia de un universo múltiple: "los entrecortados períodos que me abrumaron esa noche", "el presente era casi intolerable de tan rico y tan nítido, y también las memorias más antiguas y más triviales", "el vertiginoso mundo de Funes". "Era el solitario y lúcido espectador de un mundo multiforme, instantáneo y casi intolerablemente preciso. Babilonia, Londres y Nueva York han abrumado con feroz esplendor la imaginación de los hombres: nadie en sus torres populosas o en sus avenidas urgentes, ha sentido el calor y la presión de una realidad tan infatigable como la que día y noche convergía sobre el infeliz Ireneo, en su pobre arrabal sudamericano" $(F, 137,138,141,142)$.

En este punto habría que enlazar la angustia del infinito que siente Borges con su visión de un universo inabarcable e incomprensible para la mente humana, tema que tratamos en un estudio aparte. Baste recordar ahora que cuando crea burlonamente cuentos como "El Aleph" o "Funes el memorioso", donde el hombre alcanza el poder divino de la comprensión total del orbe, destaca su riqueza innumerable y su multiplicidad sin límites que vanamente pretenderá abrazar el ser común. Otras veces, en un ensayo como el dedicado a la metáfora esfera-Dios-universo, la inabarcabilidad se fija atendiendo a una forma de ámbito amplísimo y sin fronteras, donde el hombre vaga extraviado $(O I, 15)$ : 
... setenta años después, no quedaba un reflejo de ese fervor y los hombres se sintieron perdidos en el tiempo y en el espacio. En el tiempo, porque si el futuro y el pasado son infinitos, no habrá realmente un cuándo; en el espacio, porque si todo ser equidista de lo infinito y de lo infinitesimal, tampoco habrá un dónde. Nadie está en algún día, en algún lugar; nadie sabe el tamaño de su cara.

Por eso el laberinto de Abejacán el Bojarí $\left(A^{2}, 114\right)$ es un amplio círculo que hace pensar en Nicolás de Cusa y que se confunde con la recta infinita, por eso el pastor protestante que predica contra su dueño lo acusa de emular a la divinidad y recuerda la historia del rey perdido en el desierto, es decir en un laberinto de arena. Por eso la llanura -otro desierto de soledad, otro infinito círculo- está allí siempre igual a sí misma: "Arribaron a una estancia perdida, que está como en cualquier lugar de la interminable llanura" ( $A$, 33). En ella se enfrentará para morir Martín Fierro con el Moreno, en una pelea que parece de todos los tiempos y de todos los lugares porque es el eterno enfrentarse del hombre con su destino: "Se alejaron un trecho de las casas, caminando a la par. Un lugar de la llanura era igual a otro y la luna resplandecía" ("El fin", Nac, 11 de octubre de 1953).

\section{LAS POSTERGAGIONES INFINITAS Y EL TIEMPO CÍCLIGO}

Borges ha convertido también en tema de cuento fantástico los infinitos aplazamientos, una visión relacionada con su intuición de las aporías eleáticas, pues en ambas se trata inútil e infatigablemente de alcanzar una meta.

Aparece bajo fórmula matemática como una de las soluciones de "La biblioteca de Babel" $(F, 104)$, para encontrar al "hombre del libro", es decir al poseedor de la clave del universo, y constituye el tema central de "El acercamiento a Almotásim" (HE, 107-114; $\left.F, 39-4^{8}\right)$, que es el comentario de un libro ficticio con un subtítulo significativo: A game with shifting mirrors. Esta novela historia la búsqueda de un hombre a través de los reflejos que ha dejado en otros hombres bajo el relato de las complejas y caóticas aventuras de una peregrinación cíclica por el Indostán. Pero la carrera ascendente sugiere la posibilidad de no llegar nunca a la meta, con los dos esquemas de la recta infinita y del círculo: "la conjetura de que también el Todopoderoso está en busca de Alguien, y ese Alguien de Alguien superior (o simplemente imprescindible e igual) y así hasta el Fin -o mejor, el Sinfín- del Tiempo, o en forma cíclica" $(F, 46)$. El hecho de que la novela empiece y acabe en el mismo lugar de Bombay está ya aludiendo por su parte al eterno retorno, tema con el que se enlazan en las obras de Borges los aplazamientos y las regresiones.

Ante dos elementos que se enfrentan como dos espejos y se remi- 
ten el uno al otro, Borges vuelve a la imaginación circular ${ }^{35}$; así profundiza los problemas que le sugiere The sense of the past de Henry James (OI, 19), así semi-acaba la historia de "La busca de Averroes", vuelta irónicamente contra sí mismo:

Sentí que Averroes, queriendo imaginar lo que es un drama sin haber sospechado lo que es un teatro, no era más absurdo que yo, queriendo imaginar a Averroes sin otro material que unos adarmes de Renan, de Lane y de Asín Palacios. Sentí, en la última página, que mi narración era un símbolo del hombre que yo fui mientras la escribía y que, para redactar esa narración, yo tuve que ser aquel hombre y que, para ser aquel hombre, yo tuve que redactar esa narración, y así hasta lo infinito. (En el instante en que yo dejo de creer en él, "Averroes" desaparece) $(A, 104)$.

A la doctrina del eterno retorno ha dedicado dos ensayos y el poema "La noche cíclica". Un mismo verso "Lo supieron los arduos alumnos de Pitágoras...") abre y cierra el poema, con el artificio tan corriente en las cancioncillas y relatos folklóricos del cuento de nunca acabar. Esta estructura que podría haber sido trivial se ahonda y se hace patética acumulando elementos clásicos que unen el prestigio decorativo de la antigüedad con lo monstruoso ("la urgente Afrodita de oro", el fétido palacio del Minotauro) y citas de Nietzsche, el filósofo moderno del tiempo cíclico, compartidas como experiencias personales. Sin que falte el juego "filólogo" cuando se espera "filósofo", para que su nota levemente irónica nos recuerde, con una precisa referencia al Nietzsche helenista, el escepticismo del autor acerca de toda filosofía. Y por último la propia vida de Borges esquematizada en dos o tres símbolos esenciales. Certero en lo que no es:

El tiempo que a los hombres trae el amor o el oro, a mí apenas me deja esta rosa apagada, esta vana madeja de calles que repiten los pretéritos nombres de mi sangre... $(P, 165)$.

${ }^{35}$ Abundan en su obra estas series de encadenamientos en forma lineal o cíclica que siempre suponen el infinito. En "Cuentos del Turquestán" (véase nota 34) dice: "Que un argentino hable (y aun escriba) sobre la versión alemana de la traducción rusa de unos cuentos imaginados en el Turquestán, ya es magia superior [a] la de esos cuentos. Es un énfasis de la multiplicidad del tiempo y del espacio, es casi una invitación a la metafísica..." En "La biblioteca de Babel" deben de existir: "el catálogo fiel de la Biblioteca, miles y miles de catálogos falsos, la demostración de la falacia de esos catálogos, la demostración de la falacia del catálogo verdadero, el evangelio gnóstico de Basílides, el comentario de ese evangelio, el comentario del comentario de ese evangelio" $(F, 100-101)$. En $O I, 102$, recuerda a Kafka y el Zohar, con sus series interminables de puertas para llegar a la Gloria. En el caso de Las mil y una noches destaca su círculo eterno $(O I, 57-58)$. En Sur, núm. 73, pp. 85-86, se interesa por los silogismos bicornutos, también razonamientos de tipo cíclico, que enriquece con un ejemplo propio. 
Certero en lo que es: la emoción de eternidad sentida en una calle cualquiera del suburbio, con la que ya expresó en prosa la revelación de un vivir intemporal (cf. $O I, 210$ ss.):

pero sé que una oscura rotación pitagórica noche a noche me deja en un lugar del mundo que es de los arrabales. Una esquina remota que puede ser del norte, del sur o del oeste, pero que tiene siempre una tapia celeste, una higuera sombría y una vereda rota.

Calle vista platónicamente -diríamos con palabras del mismo Borges-, es decir, reducida a sus notas poéticas esenciales por un proceso de decantación de su propio arte.

La ciudad amada, belleza y melancolía, es la "rosa apagada" que se le convierte en el laberinto sin salida de su destino y de todo destino humano, laberinto ya insinuado en los primeros versos por el recuerdo del Minotauro y ahora aludido nuevamente con un lenguaje que borra los contornos ("apenas", "apagada", "vana"), y que sustituye realidades por elementos oníricos:

Las plazas agravadas por la noche sin dueño son los patios profundos de un árido palacio y las calles unánimes que engendran el espacio son corredores de vago miedo y de sueño.

Así llegamos al misterio de una noche que vuelve a ser la primera noche, de un acto - el acto creador del poeta, lo más único e insustituible- que se nos convierte en la escritura incesante de un autómata $^{36}$.

En "El tema del traidor y del héroe" $(F, 156-157)$, "El jardín de senderos que se bifurcan" $(F, 120)$, "Tres versiones de Judas" ( $F$, 198-199), "Tlön, Uqbar, Orbis Tertius" $(F, 30)$, "La biblioteca de Babel" ( $F, 107)$, "El inmortal" ( $A, 21$ y 24) ha introducido Borges alusiones pasajeras al tiempo cíclico, y ya vimos que la repetición de alucinaciones daba horror a "El milagro secreto" $\left(F, 18_{3}, 186\right.$, 189). "Los teólogos", cuento basado en el tema de la identidad personal, se carga de pasión, de misterio y de extrañeza con la doctrina cíclica puesta en boca de los heresiarcas (monótonos, anulares) y con sus símbolos de la rueda y la serpiente. Citas de San Agustín, de Plutarco, de los estoicos, de Orígenes, de Cicerón, de Plinio, de las

${ }^{36}$ La visión del escritor como no creador es insistente en la obra de Borges. Además de presentarse, como en este poema, bajo la forma del tiempo. cíclico, aparece relacionada con la idea del número finito de combinaciones posibles de los signos alfabéticos en "La biblioteca total" y en "La biblioteca de Babel"; con la idea de simples amanuenses de la Divinidad que dicta; con la visión nihilista del ejercicio literario. "Pierre Menard, autor del Quijote" es la fabulación de la actitud de un hombre que conscientemente se adelanta a realizar una tarea simbólica de ese nihilismo. 
Sagradas Escrituras, "fábulas gentiles que perduraban rebajadas a adornos" ( $A, 39)$, dan el tono erudito y el sabor de las disputas teológicas. Las terribles palabras del heresiarca Euforbo quemado en la pira insinúan la infinita repetición del mismo drama y nos sumergen en la pesadilla circular y eterna, pero al mismo tiempo anuncian la tragedia de los dos teólogos enemigos que morirán también entre las llamas, con una doble alusión al Eterno Retorno y a una panteística identidad de todos los destinos humanos $(A, 41)$.

Borges ha dedicado dos artículos a la doctrina cíclica; pero, más que seguirlo en los pormenores de la doctrina misma, nos interesa destacar su actitud ante el problema. Vuelve a encontrarse el escepticismo de siempre por cualquier especulación filosófica, vista como un hallazgo estético y no como una verdad: "El roce del hermoso juego de Cantor con el hermoso juego de Zarathustra es mortal para Zarathustra" (HE, 61). También vuelve a encontrarse la atracción que sobre él ejerce una imaginación monstruosa y patética a la vez: "Antes de Nietzsche la inmortalidad personal era una mera equivocación de las esperanzas, un proyecto confuso. Nietzsche la propone como un deber y le confiere la lucidez atroz de un insomnio... Desenterró la intolerable hipótesis griega de la eterna repetición y procuró educir de esa pesadilla mental una ocasión de júbilo" ( $H E$, $\left.64^{-65}\right)$.

Borges relaciona con el tiempo cíclico otra invención monstruosa: la biblioteca abarcadora de todas las obras presentes, pasadas y futuras, formadas con las posibles combinaciones de los veinticinco signos alfabéticos. Parece justo establecer tal comparación pues, dado el número finito de elementos (en los libros los signos alfabéticos, en el universo los átomos), llegamos a un número fijo de combinaciones que debemos repetir cuando se han agotado. Pero no deja de llamar la atención que Borges derive una imaginación de lo finito a una pesadilla enloquecedora de lo infinito ${ }^{37}$.

En su ensayo "La biblioteca total" historia el origen de la idea desde Aristóteles hasta Laswitz, y ya se siente la tragedia que encierra como símbolo del incomprensible destino humano: "Todo, pero por una línea razonable o una justa noticia habrá millones de insensatas cacofonías, de fárragos verbales y de incoherencias. Todo, pero las generaciones de los hombres pueden pasar sin que los anaqueles vertiginosos - los anaqueles que obliteran el día y en los que habita el caos- les hayan otorgado una página tolerable" (Sur, núm. 59, p. 16). Estos anaqueles nos inician en la metáfora biblioteca-universo desarrollada luego en su ficción de "La biblioteca de Babel".

s7 En "El truco", el mismo cálculo de probabilidades, con un número fijo de elementos, sirve para anular el tiempo y probar la eternidad ( $P$, 21-22; $I A, 34)$. 
Aquí la arquitectura del edificio, con los espejos que lo duplican, las innumerables galerías hexagonales, los pozos de ventilación vastos e insondables, las escaleras de caracol que se desenvuelven interminablemente, el vacío donde los cadáveres se desintegran, la construcción laberíntica de galerías repetidas, la luz incesante de las lámparas, traen el concepto angustioso de lo infinito. También se oculta Dios bajo las formas de la esfera y del círculo en que se trasmutan los polígonos de la biblioteca y los libros, recordándonos otro símblo de lo inabarcable. Ya vimos, además, que los aplazamientos sin fin aparecían como una de las soluciones para encontrar al "hombre del libro" poseedor del secreto del mundo.

Toda esta opresión desemboca en la ansiedad del hombre que acaba por sentirse perdido en una doble inmensidad: la de la riqueza agobiadora del orbe o la del eterno peregrinar cíclico. Porque si en un momento pensó que el número fijo de las combinaciones alfabéticas ponía a su alcance su justificación y la clave de su destino, la monstruosidad de la biblioteca-universo lo aplasta con una cifra que, siendo finita, se torna inabarcable para la vida humana: "Las vindicaciones existen (yo he visto dos que se refieren a personas del porvenir, a personas acaso no imaginarias), pero los buscadores no recordaban que la posibilidad de que un hombre encuentre la suya, o alguna pérfida variación de la suya, es computable en cero" ( $F$, 101-102). Y como si esto no bastara, lo lanza a un eterno peregrinar cíclico a través de las reiteradas galerías de la arquitectura monstruosa o inmutable:

Yo me atrevo a insinuar esta solución del antiguo problema: La Biblioteca es ilimitada pero periódica. Si un eterno viajero la atravesara en cualquier dirección, comprobaría al cabo de los siglos que los mismos volúmenes se repiten en el mismo desorden (que, repetido, sería un orden: el Orden) . Mi soledad se alegra con esa elegante esperanza" $(F, 107)$.

Elegante es ahora la adjetivación que corresponde al eterno retorno. Se ha destacado en Borges su capacidad de asombrarse ante el misterio del universo, pero se diría que lo fundamental en él es su capacidad de maravillarse ante las imaginaciones de los hombres que intentan interpretar un mundo definitivamente impenetrable. La invención de Dios, de la Trinidad, del cielo y del infierno, de los arquetipos platónicos, del panteísmo y tantas otras construcciones religiosas o filosóficas que sus creadores consideran la justa explicación de la realidad, entusiasman a Borges, que las mira gozando de su magia y de la capacidad imaginativa del hombre.

Ana María Barrenechea

Instituto de Filología,

Buenos Aires. 